Proceedings

\title{
Assessing the Influence of Environmental and Physiographic Parameters on Common Bottlenose Dolphin (Tusiops truncatus) Distribution in the Southern Adriatic Sea ${ }^{\dagger}$
}

\author{
Aurelie Muckenhirn 1,2, Aylin Akkaya Bas ${ }^{2}$ and Freddie-Jeanne Richard 1,*
}

Citation: Muckenhirn, A.; Bas, A.A.; Richard, F.-J. Assessing the Influence of Environmental and Physiographic Parameters on Common Bottlenose Dolphin (Tusiops truncatus)

Distribution in the Southern Adriatic Sea. Proceedings 2021, 65, $x$,

doi:10.3390/xxxxx

Academic Editor:

Published: date

Publisher's Note: MDPI stays neutral with regard to jurisdictional claims in published maps and institutional affiliations.

Copyright: (C) 2021 by the authors. Submitted for possible open access publication under the terms and conditions of the Creative Commons Attribution (CC BY) license (http://creativecommons.org/licenses/by/4.0/).
1 Laboratoire Ecologie et Biologie des Interactions UMR CNRS 7267, Equipe "Ecologie, Evolution, Symbiose", Université de Poitiers, Poitiers, France; amuckenhirn@gmail.com

2 Deniz Memelileri Araştırma Derneği, Marine Mammals Research Association (DMAD), Bar, Montenegro; akkayaaylinn@gmail.com

* Correspondence: amuckenhirn@gmail.com or freddie.jeanne.richard@univ-poitiers.com; Tel.: +33-1-(805)-8869456

+ Presented at the 1st International Electronic Conference on Biological Diversity, Ecology and Evolution, 15-31 March 2021; Available online: https://bdee2021.sciforum.net/.

\begin{abstract}
The Mediterranean subpopulation of common bottlenose dolphins, Tursiops truncatus, is classified as vulnerable by the IUCN Red list due to its decline in population size by at least $50 \%$ within the last 50 years. Identifying the spatial distribution and habitat characteristics of this species is crucial to develop effective conservation and ecosystem management strategies. This research is designed to understand the effect of external parameters on the distribution of bottlenose dolphins off the coast of Montenegro. The northern and central Adriatic Sea have been comparably studied since the 1980s, however the southern Adriatic Sea is suffering from a lack of baseline knowledge. Data collected from boat and land surveys over the past 2 years was utilized to create a Species Distribution Model (SDM). A random forest model incorporating environmental and physiographic variables to represent the dynamic nature of common bottlenose dolphins is applied. These variables include sea surface temperature (SST), salinity, nutrients (Phosphorus and Nitrogen), bathymetry, slope and distance to coast. The results identified distance to coast, bathymetry, phosphorus and slope as the principal explanatory variables influencing bottlenose dolphin distribution in the southern Adriatic Sea. Bottlenose dolphins were more commonly spotted in shallow waters $(<100$ $\mathrm{m})$, in areas with a lower degree of slope (0.06-2.36), with higher phosphorus levels $(>0.005 \mathrm{mmol}$ $\mathrm{m}-3$ ) and between 760 to $2900 \mathrm{~m}$ off the coast of Montenegro.
\end{abstract}

Keywords: marine mammals; marine ecosystem management; Mediterranean Sea; cetaceans

\section{Introduction}

All marine ecosystems, including the ones found in the Mediterranean, are an indispensable part of human livelihood and natural processes making their management and conservation essential. The Mediterranean Sea is considered as the largest and deepest enclosed sea on Earth, located between Africa, Europe and Asia bordered by 46,000 km of coastline [1]). It hosts $7 \%$ of the world's marine biodiversity with over 17,000 species including a large amount of endemic species. Additionally, the Mediterranean Sea harbors sensitive endangered habitats such as seagrass meadows, seamounts, mud volcanoes [2].

Cetaceans are commonly found at the top of trophic chains worldwide from the poles to the equator throughout a range of habitats. They assist in nutrients cycling and enhance primary productivity making them fundamental drivers of marine ecosystem function- 
ing, consequently their conservation is imperative [3]. The multitude of threats facing cetaceans can lead to severe changes in marine ecosystems and the services they provide. Cetaceans are indicators of marine ecosystem health; therefore, their protection is necessary for ensuring biodiversity and socio-economic benefits [4].

Common bottlenose dolphins are distributed worldwide excluding the Arctic and Antarctic Circle regions due to their preference for temperate and tropical waters. Reproduction, migration and foraging, as well as the influence of physical and biological oceanic characteristics affect this species distribution cycle [5]. They can be found inhabiting a range of areas such as continental shelf waters, lagoons, estuaries, enclosed seas and waters surrounding islands and archipelagos. Additionally, they are occasionally spotted off shore in waters as deep as $2000 \mathrm{~m}$ [6]. There are two species present within the genus Tursiops: the common bottlenose dolphin T. truncatus and the Indo-Pacific bottlenose dolphin T. aduncus. However only T. truncatus can be found in the Mediterranean Sea and North Atlantic Ocean [7]. The common bottlenose dolphin, thereafter referred to as bottlenose dolphin, Tursiops truncatus is one of the most widely studied cetaceans in the Mediterranean Sea and considered as an umbrella species, making them an important species to conserve $[3,8]$.

Bottlenose dolphins in the Mediterranean Sea are protected under the EU Integrated Maritime Policy, composed of the Habitat Directive, Bird Directive, and Marine Strategy Framework Directive (MSFD) adopted in 2008. The MSFD aims to achieve Good Environmental Status (GES) in marine waters by maintaining biodiversity. To establish GES, a framework detailing a set of marine management strategies must be developed by each member state (European Commission, 2015). For this framework to contain effective indicators and management strategies, knowledge regarding the distribution of target species, location of critical habitats and the impact or pressure exerted from human activities is crucial. This will assist in establishing baseline data for future assessments of marine areas [1]. Further, the MSFD marine management strategies will contribute to creating a coherent network of Marine Protected Areas (MPAs). The objective of these areas is to protect habitats that contain entire populations or are of vital use to the species. For example, protecting habitat patches utilized by Bottlenose dolphins for feeding, socializing, breeding or resting [9].

Currently there are only around one hundred MPAs varying in type, size and purpose in Algeria, Croatia, Cyprus, France, Greece, Israel, Italy, Lebanon, Malta, Monaco, Morocco, Slovenia, Spain, Syria, Tunisia and Turkey. However, most of their management plans exclude marine mammal specific protection strategies. An exception of this, is the Pelagos Sanctuary, extending about 90,000 $\mathrm{km}^{2}$ in the north-western Mediterranean Sea between Italy, France and Sardinia [10]. Another exception to this occurred in 2006, when three years of provisional protection was established in the waters east of the islands of Losinj and Cres in Croatia to protect dolphins. Nevertheless, this period expired without the establishment of any permanent protection measures. The adaptation of SAC and MPA boundaries to encompass new findings on cetacean distribution, range patterns and critical habitats is vital [3]. These designated areas could be linked to create ecological corridors protecting migration routes.

Unfortunately, the MPAs already established in the Mediterranean Sea have been referenced as being nothing more than 'paper parks,' due to a lack of implementation and enforcement [11]. To successfully protect bottlenose dolphin populations from various anthropogenic and environmental changes, the establishment and strict enforcement of ecosystem-based management and conservation guidelines are necessary. The development of such guidelines relies on defining bottlenose dolphin critical habitats. The Southern Adriatic Sea boasts some of the richest cetacean habitats and is home to year-round bottlenose dolphin groups $[8,12,13]$. However, insufficient research in this area has created a data deficient gap halting the creation of legislative framework to regulate anthropogenic activities and define areas of protection. 
The first research on bottlenose dolphins in the Mediterranean Sea began in the 1980s [7]. In the 19th century, dolphins were abundantly found throughout the Mediterranean Sea. These cetaceans were viewed as vermin specifically by fishery managers, which led to campaigns and the intentional killing of thousands. The population size of bottlenose dolphins in the Mediterranean Sea is currently unknown due to a lack in basin wide studies, and suspected to be as low as the 10,000 s. The Mediterranean Sea population of bottlenose dolphins has reduced by 30\% since the 1940s [14]. Followed by an even larger decline of at least $50 \%$ over the last 50 years. This decrease in population has caused the IUCN red list for threatened species to classify bottlenose dolphin Mediterranean subpopulation as vulnerable since 2006 [7]. Their once widespread distribution throughout European, African and Asian continental shelves from Gibraltar to the Black Sea, has shrunk dramatically and become fragmented [8]. Their distribution is now separated by naturally occurring or anthropogenically induced gaps of low densities. These low-density gaps have been documented in north-western Ligurian Sea and north-western Gulf of Vera [7].

Two bottlenose dolphin populations have been identified within the Mediterranean, the western Mediterranean population and eastern Mediterranean population [15]. Further genetic analysis revealed the presence of five subpopulation from the Tyrrhenian Sea to the Aegean Sea. An additional subdivision of these subpopulations was recorded in the Adriatic Sea. Population differences between the north and central-south areas of the Adriatic may be due to physiographic variances such as different depth gradients and water mass circulations. Subdivisions were also found between the west and east coasts, the west coast is characterized as being sandy, whereas the east coast is a karst topography which could be responsible for the differentiation of subpopulations [16]. While northern and central Adriatic Sea has been comparably studied since 1980s, the south part, specifically the east coasts, suffer from the lack of baseline knowledge [7,12]. Majority of the studies were targeted around species presence, distribution, photo-identification, residencies and the impact of marine traffic whereas there are comparably few studies on population sizes or habitat modelling in the Adriatic Sea [12]. Research has found that the Northern Adriatic local population hosts around 140 individuals [8,17]. However, population numbers for the Central and Southern Adriatic Sea are just recently being investigated.

Information regarding the spatial distribution of target species is necessary to develop effective indicators and management actions for the preservation of marine biodiversity. However, understanding how environmental, physiographic and anthropogenic variables impact this distribution can be viewed as more important as it allows us to predict areas of spatial distribution while considering changes on a global scale [18]. Previous research has shown that environmental variables such as chlorophyll-a levels, SST and salinity play a role in defining bottlenose dolphin critical habitats $[1,3,4,19]$. Additionally, physiographic variables including distance to coast and bathymetry have been correlated with this species distribution $[1,4]$. Shifts in these variables due to anthropogenic or natural causes are capable of shaping bottlenose dolphin critical habitats, affecting their abundance and distribution [20].

This paper explores the spatial distribution and habitat preferences of bottlenose dolphins in the Southern Adriatic Sea. The objective of this research is to show how environmental and physiographic variables affect the population of bottlenose in order to gain necessary knowledge to pinpoint critical areas for the establishment of the first SAC and MPA in the Southern Adriatic Sea.

\section{Experiments}

\subsection{Methods and Materials}

\subsubsection{Study Area and Data Collection}

The survey area covered the entire Montenegrin coastline of $293 \mathrm{~km}$, between Herceg Novi and Ada Bojana, and territorial waters (Figure 1). Surveys were conducted during 
the period of 15 September 2016 to 26 April 2018. Surveys were conducted by land and boat.

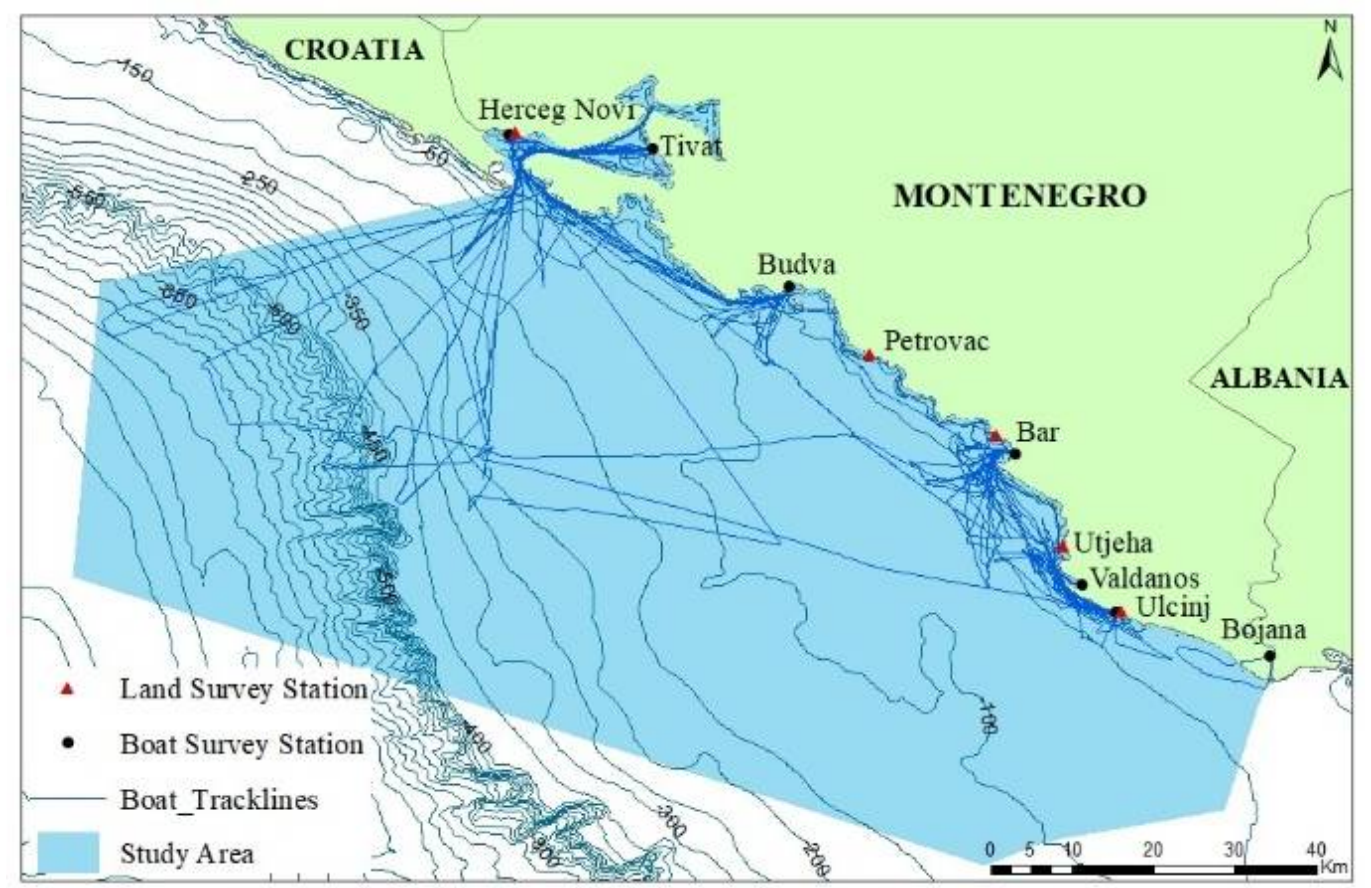

Figure 1. A map of the study area displaying land and boat survey stations including boat research effort from September 2016-April 2018 and bathymetry contours.

Land surveys were conducted regularly throughout the year from 5 pre-determined stations (Figure 1), lasting between 3-5 h during sunrise or sunset. Land stations were selected to cover the entire Montenegrin coastline located in areas which maximize the likelihood of dolphin sightings. A theodolite and binoculars were used to survey the ocean. The theodolite determines the vertical and horizontal angles of the target subject(s) when present. Pythagoras (Version 1.2), a tracking software was utilized to transfer the theodolite readings into geographic coordinates based on predetermined reference point and azimuth. This software also recorded observation height and geographic position for each land survey station. Pythagoras determines the path and velocity of the target subject(s), the focal dolphin group.

Boat surveys were conducted once weekly, dependent on weather conditions and boat availability. Surveys only took place when the sea was calm with a Beaufort between $0-3$ and good visibility ( $>1$ mile). Surveys lasted $4-7 \mathrm{~h}$ during sunrise or sunset and were conducted in randomly selected areas leaving from 4 departure points (Figure 2). The marine vessels used were either 6-m outboard engine fishing boat or a 12-m outboard engine speed boat. The vessel traveled at an average of 3 knots. Geographic Positioning System (GPS) was utilized to record the geographic position of the observation vessel every $3 \mathrm{~s}$. When dolphin(s) were present, the angle and approximate distance of the dolphin(s) from the research vessel was determined. 


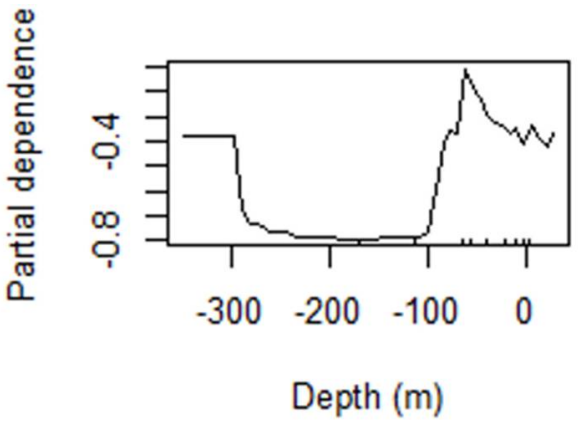

(a)

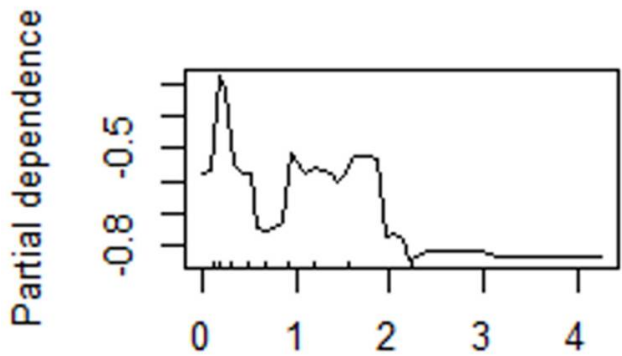

Slope $\left({ }^{\circ}\right)$

(c)

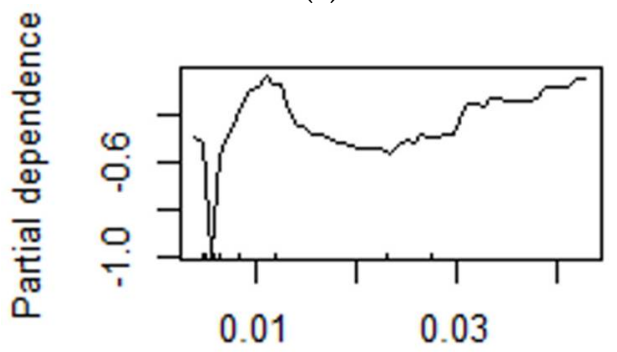

Phosphorus ( $\mathrm{ml} \mathrm{mol} \mathrm{m-3)}$

(e)

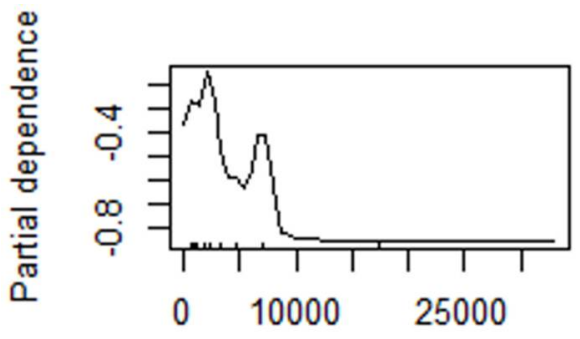

Distance to coast (m)

(b)

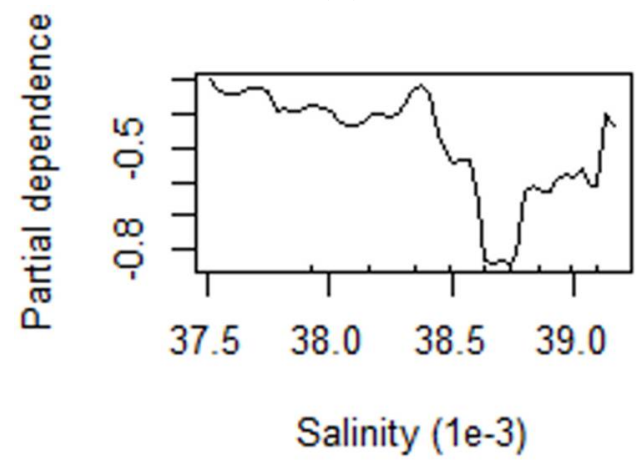

(d)
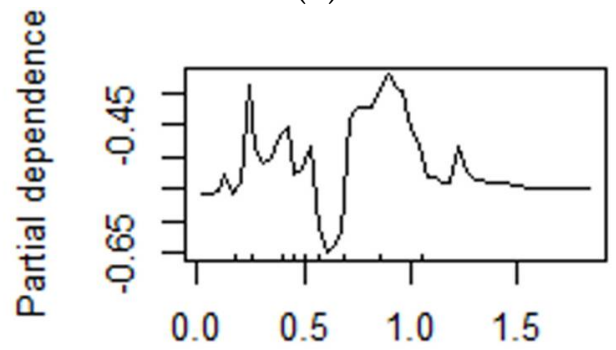

Nitrogen $(\mathrm{ml} \mathrm{mol} \mathrm{m-3)}$

(f)

Figure 2. Univariate partial dependence plots of the environmental and physiographic variables: depth (a), distance to coast (b), slope (c), phoshphorus (d), salinity (e), and nitrogen (f).

\subsubsection{Data Analysis}

Data on physiographic and environmental features were collected for the entire study area. The environmental variables utilized for this model were sea surface temperature (SST) $\left({ }^{\circ} \mathrm{C}\right)$, salinity $(1 \mathrm{e}-3)$ and nutrients (phosphorus and nitrogen) $(\mathrm{mmol} \mathrm{m}-3)$ (Table 2). The physiographic variables used in this model were depth $(\mathrm{m})$, distance to coast $(\mathrm{m})$ and slope $\left({ }^{\circ}\right)$. Environmental variables were chosen based on literature review and downloaded from Copernicus Marine Environment Monitoring Service in the form of high temporal resolution products (NetCDF files) with a horizontal grid resolution of $1 / 24^{\circ}$ (ca. $4 \mathrm{~km}$ ) $[1,3,4,19]$. Bathymetry was downloaded from European Marine Observation and Data network (EMODnet) with a grid size of $1 / 8 * 1 / 8$ arc minutes of longitude and latitude. The daily average of each environment variable was selected to closely resemble in situ measurements.

To incorporate downloaded environmental variables, Arcmap 10.5.1 was used. Downloaded environmental data was converted from netCDF to Tiff files using multidimension toolbox "make a netCDF raster layer". Then the missing gaps near the coastline in the raster layer were filled using Focal Stats. The boat track line shp file was separated into dolphin presence and absence. A buffer of $4850 \mathrm{~m}$ was created around each individual boat track line where dolphins were present and absent using the analysis toolbox "create 
a buffer". The size of the buffer, $4850 \mathrm{~m}$, was determined by the resolution of the downloaded environmental data. Following, the data management tool "create random points" was used to automatically generate random background points with a minimum allowed distance of $4850 \mathrm{~m}$ for each boat track line. These random points represent pseudo-absences. Under spatial analysis toolbox "zonal statistics" were used to attain the mean of each environmental variable within the buffer zone where dolphins were sighted. The spatial analysis toolbox "extract multi values to points" was applied to points where dolphins were absent within the buffer zone to attain the mean of each environmental variable.Using the bathymetry raster, the slope was calculated with spatial analysis toolbox "slope". Additionally, the analysis toolbox "near analysis" was applied to calculate distance to shore from all dolphin presence and absence points. To identify areas of most likely occurrence of dolphins, the spatial analysis toolbox "kernel density" was utilized.

Within R studio (Version 3.4.3), Spearman's rank correlation coefficient analysis was applied to identify high correlation $(>0.7)$ between any predictor variables. A high correlation was identified between SST and Salinity. SST was excluded from the following model given literature reviews which indicated that bottlenose dolphins are homeotherms and therefore not highly impacted by changes in SST (La Manna et al., 2016).

To model the relationship between the above mentioned variables and bottlenose dolphin distribution, the Random Forest (RF) algorithm was implemented using the "caret" package within R studio. Variable importance is measured as a result of looking at the deterioration of the predictive ability of the model when each predictor is replaced in turn by random noise. The variable importance is measured as the mean decrease in Gini coefficient. After the most important variables have been identified, partial dependence plots are created to understand the nature of the dependence of the response variable on each explanatory variable. Partial dependence plots visualize the relationship between each individual explanatory variable and the probability of presence [21].

\section{Results}

\subsection{Bottlenose Dolphing Habitat Preference}

\subsubsection{Habitat Variable Correlation}

Data analysis of sea surface temperature (SST) and salinity were significantly correlated (Spearman's rank correlation $r=0.76$. This correlation resulted in the elimination of SST from the Random Forest model.

\subsubsection{Dolphin Occurrence and Predictor Variables}

The relationship between the presence and absence of individuals, environmental and physiographic variables was evaluated with the optimal RF model. Based on the RF model, the spatial distribution of bottlenose dolphins was mostly driven by distance to coast $(\sim 100 \%)$, depth $(\sim 60 \%)$, slope $(\sim 50 \%)$ and phosphorus $(\sim 60 \%)$ (Figure 5$)$. Salinity $(\sim 0 \%)$ and nitrogen $(\sim 20 \%)$ resulted poorly for the determination of bottlenose dolphin distribution (Figure 3). For each variable, univariate partial dependence plots identified the range of optimal values expected to increase presence probability in the RF model (Figure 2). The influence of distance to coast values on the spatial distribution of bottlenose dolphins show a threshold level for low probability of occurrence further than 10,000 $\mathrm{m}$. A decreasing trend as distance to coast increased was also found (Figure 2). The second explanatory variable influencing bottlenose dolphin spatial distribution was depth which revealed a threshold level with low probability of presence in waters of more than $100 \mathrm{~m}$ in depth (Figure 2), a peak after $300 \mathrm{~m}$ of depth is present. The influence of slope on the spatial distribution of bottlenose dolphins identified a threshold level for low probability of occurrence at a slope greater than $2^{\circ}$ (Figure 2 ). Phosphorus showed relevant variable effect on their spatial distribution. An abrupt increase in probability of occurrence was detected at higher levels of phosphorus, $>0.005 \mathrm{mmol} \mathrm{m}-3$ (Figure 2). 


\section{Random Forest Variable Importance}

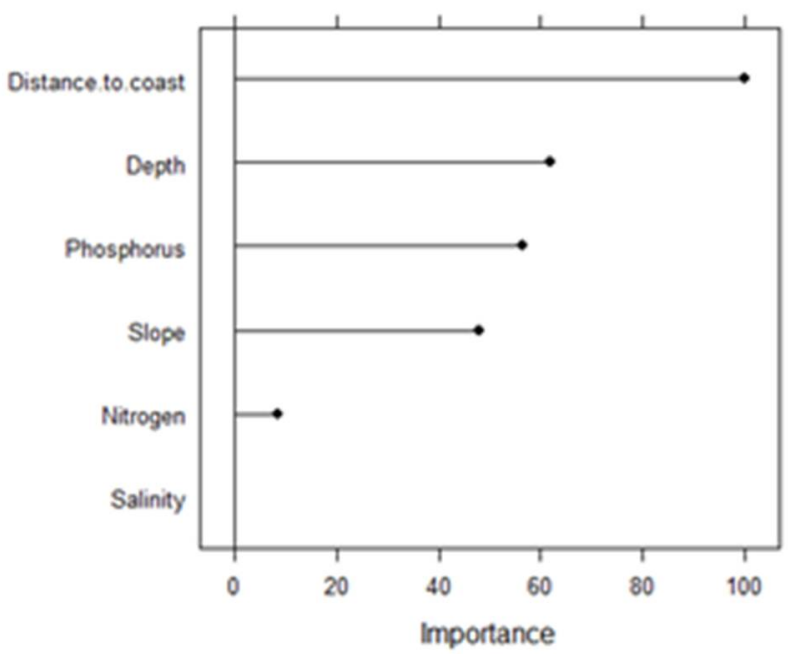

Figure 3. Plot of relative variable importance $(\%)$ as determined by random forest model (Max = 100).

\section{Discussion}

The distribution of a species can be described as a tradeoff relationship between the benefits a specific habitat provides, and the risks taken from inhabiting or frequenting such an area [3]. In this study, RF model analysis weighed the contribution of environmental and physiographic variables on bottlenose dolphin habitat preference. The principle variables that define the spatial distribution of bottlenose dolphins in Montenegrin waters are distance to coast, depth, slope and phosphorus.

In the Mediterranean Sea, bottlenose dolphins prefer being near the coast with highest occurrence between $700 \mathrm{~m}$ and $1370 \mathrm{~m}$ [3]. The variable with the greatest influence on bottlenose dolphin distribution in the RF model was distance to coast. Bottlenose dolphins were found to be present between 371 and $7080 \mathrm{~m}$. The area with the highest likelihood of dolphin occurrence was between 760 and $2900 \mathrm{~m}$ from the coastline. Although primarily a coastal species, in some areas of the Mediterranean bottlenose dolphins have been found up to $5000 \mathrm{~m}$ from the coastline [1,22]. Therefore, this particular study revealed that bottlenose dolphins in Montenegrin waters are found slightly further off coast than in other Mediterranean areas.

Depth was another important factor influencing habitat preference of bottlenose dolphins. In current study, we found that bottlenose dolphins present between $24 \mathrm{~m}$ and 350 $m$ depth zones. Shallow waters are known for harboring cetaceans because of their abrupt topography. Bottlenose dolphin preference for shallow waters can be linked to the use of preferred feeding grounds, as neritic waters have often been identified as hosting complex and rich food webs [3]. These food webs include seagrass beds and rocky reefs which host a variety of demersal prey including European hake Merluccius merluccius and European conger Conger conger, commonly consumed by bottlenose dolphins [7]. Previous research pointed out that bottlenose dolphins seem to increase their presence in these areas as it increases their chances of finding preferential (demersal) prey. Research in the northern Adriatic Sea found that bottlenose dolphins are five times more likely to prefer neritic zone areas than oceanic zone areas [23]. Here we observed bottlenose dolphin presence in areas reaching $350 \mathrm{~m}$ of depth, previous research observed depths between $100 \mathrm{~m}$ and 400 $m[16,20,24]$. The bathymetry of the Adriatic Sea (Figure 1) indicates an abrupt change in depth when entering the southern portion, potentially explaining the occurrence of bottlenose dolphins in deeper waters $(\sim 350 \mathrm{~m})$. However, Research across the whole Medi- 
terranean revealed that most bottlenose dolphins $(78 \%)$ were observed within the continental shelf $(<200 \mathrm{~m})$, though this species could also be encountered in the upper continental slope (200-1000 m) [25].

The preference for areas with lower slope and shallow water by bottlenose dolphins has been previously observed [4]. This study found that slope was another indicator of their distribution in Montenegrin waters. The southern Adriatic Sea is flanked by a steep and rugged slope [26]. Bottlenose dolphins were found to inhabit areas of lower slope, $0.06-2.36^{\circ}$. It is known that slope degree impacts bottom topography, tidal movements and therefore the distribution of potential prey.

The availability of phosphorus can strongly affect the marine carbon cycle as it is a limiting factor for primary production [27]. Phosphorus levels were found to influence the probability of occurrence of bottlenose dolphins, with areas containing higher levels of phosphorus (>0.005) having more likely probability of occurrence of the species. An increase in phosphorus causes an increase in primary production, thus influencing the distribution of zooplankton and indirectly of zooplankters fish [3]. Therefore, the link between bottlenose dolphin distribution and phosphorus observed in our study is likely attributed to prey distribution.

Previous research has shown an increase in the probability of occurrence of bottlenose dolphins with increasing levels of nitrogen as it helps stimulate primary and secondary production [28]. This study categorized nitrogen as a poor explanatory variable for the distribution of the species. Additionally, Salinity levels within the ocean vary depending on distance to freshwater source, season and tides. Bottlenose dolphins are found inhabiting a variety of salinity levels which may be linked to salinities influence on prey distribution, particularly estuarine species [29]. However, this variable did not prove to be a primary influence on bottlenose dolphin distribution in the southern Adriatic Sea.

\section{Conclusions}

In the current study, our model identified environmental and physiographic variables influencing the distribution of bottlenose dolphins in the territorial waters of Montenegro, the southern Adriatic Sea. The importance of local physiography (distance to coast, depth, slope) as well as phosphorus levels were highlighted as key factors. These results primarily concur with previous research in other areas of the Mediterranean Sea. The inferences made from these results help to understand how this species uses its habitat, which further allows for the development of management and conservation strategies for this area.

Cetacean habitat boundaries are difficult to define as they are wide-ranging, migratory marine animals. Nonetheless, it is characteristics like these that make bottlenose dolphins umbrella species, thus analyzing which environmental and physiographic variables influence their distribution is a crucial step for conserving marine ecosystems. The identification of the strongest variables affecting attraction or avoidance for this species can be utilized by MSFD and marine spatial planning (MSP) for the placement and size of MPAs/SACs.

Montenegro's economy relies heavily on tourism therefore Ramsar and UNESCO terrestrial sites have been implemented. However, regarding coastline and marine conservation no MPAs or SACs have been established [30]. The results of this study allow for the future creation of habitat suitability maps which will identify specific areas preferred by bottlenose dolphins in Montenegrin waters. The identification of these suitable habitats combined with knowing how dynamic and static variables influence bottlenose dolphin distribution will allow for the placement of accurate and effective marine management strategies, as well as the creation of the first MPA or SAC in the southern Adriatic Sea.

Author Contributions: A.M., A.A.B. and F.-J.R. conceived and designed the experiments; A.M. and A.A.B. performed the experiments; A.M. analyzed the data; Aylin Akkaya Bas contributed data that 
had been previously collected; A.M., A.A.B. and F.-J.R. wrote the paper. All authors have read and agreed to the published version of the manuscript.

\section{Institutional Review Board Statement:}

\section{Informed Consent Statement:}

\section{Data Availability Statement:}

Acknowledgments: The Montenegro Dolphin Project team who participated with field work and data collection. Nikolina Mileva and Mehmet Akif Erdogan contributions to data analysis. Financial assistance was provided by the Fondation at the Universite de Poitiers, France. This research was also supported by the European Commission through the program, Erasmus Mundus Master Course-International Master in Applied Ecology (EMMC-IMAE) (FPA 2023-0224/532524-1-FR2012-1-ERA MUNDUS-EMMC) - Coordinator F-J Richard, Université de Poitiers.

Conflicts of Interest: The authors declare no conflict of interest.

\section{Abbreviations}

The following abbreviations are used in this manuscript:

RF: Random Forest

\section{References}

1. Carlucci, R.; Fanizza, C.; Cipriano, G.; Paoli, C.; Russo, T.; Vassallo, P. Modeling the spatial distribution of the striped dolphin (Stenella coeruleoalba) and common bottlenose dolphin (Tursiops truncatus) in the Gulf of Taranto (Northern Ionian Sea, Central-eastern Mediterranean Sea). Ecol. Indic. 2016, 69, 707-721, doi:10.1016/j.ecolind.2016.05.035.

2. Coll, M.; Piroddi, C.; Albouy, C.; Ben Rais Lasram, F.; Cheung, W.W.; Christensen, V.; Karpouzi, V.S.; Guilhaumon, F.; Mouillot, D.; Paleczny, M.; et al. The Mediterranean Sea under siege: Spatial overlap between marine biodiversity, cumulative threats and marine reserves. Glob. Ecol. Biogeogr. 2012, 21, 465-480, doi:10.1111/j.1466-8238.2011.00697.

3. La Manna, G.; Ronchetti, F.; Sarà, G. Predicting common bottlenose dolphin habitat preference to dynamically adapt management measures from a Marine Spatial Planning perspective. Ocean Coast. Manag. 2016, 130, 317-327, doi:10.1016/j.ocecoaman.2016.07.004.

4. Pennino, M.G.; Merigot, B.; Fonesca, V.P.; Monni, V.; Rotta, A. Habitat modeling for cetacean management: Spatial distribution in the southern Pelagos Sanctuary (Mediterranean Sea). Deep. Sea Res. Part II Top. Stud. Oceanogr. 2017, 141, 203-211, doi:10.1016/j.dsr2.2016.07.006.

5. Lambert, C.; Laran, S.; David, L.; Dorémus, G.; Pettex, E.; Van Canneyt, O.; Ridoux, V. How does ocean seasonality drive habitat preferences of highly mobile top predators? Part I: The north-western Mediterranean Sea. Deep. Sea Res. Part II Top. Stud. Oceanogr. 2017, 141, 115-132, doi:10.1016/j.dsr2.2016.06.012.

6. Bearzi, G.; Fortuna, C.M.; Reeves, R.R. Ecology and conservation of common bottlenose dolphin Tursiops truncatus in the Mediterranean Sea. Mammal Rev. 2009, 39, 92-123, doi:10.1111/j.1365-2907.2008.00133.x.

7. Bearzi, G.; Fortuna, C.M.; Reeves, R.R. Ecology and conservation of common bottlenose dolphins Tursiops truncatus in the Mediterranean Sea. Mammal Rev. 2009, 39, 92-123, doi:10.1111/j.1365-2907.2008.00133.

8. Bearzi, G.; Notarbartolo-di-Sciara, G.; Politi, E. Social ecology of bottlenose dolphins in the Kvarnerić (northern Adriatic Sea). Mar. Mammal Sci. 1997, 13, 650-668, doi:10.1111/j.1748-7692.1997.tb00089.

9. Baş, A.A.; Amaha Öztürk, A.; Öztürk, B. Selection of critical habitats for bottlenose dolphins (Tursiops truncatus) based on behavioral data, in relation to marine traffic in the Istanbul Strait, Turkey. Mar. Mammal Sci. 2015, 31, 979-997, doi:10.1111/mms.12202.

10. Notarbartolo di Sciara, G.; Hyrenbach, D.; Agardy, T. The Pelagos Sanctuary for Mediterranean Marine Mammals. Aquat. Conserv. Mar. Freshw. Ecosyst. 2008, 18, 367-391, doi:10.1002/aqc.855.

11. Guidetti, P.; Milazzo, M.; Bussotti, S.; Molinari, A.; Murenu, M.; Pais, A.; Spanò, N.; Balzano, R.; Agardy, T.; Boero, F.; et al. Italian marine reserve effectiveness: Does enforcement matter? Biol. Conserv. 2008, 141, 699-709, doi:10.1016/j.biocon.2007.12.013.

12. Baş, A.A.; Affinito, F.; Martin, S.; Vollmer, A.; Gansen, C.; Morris, N.; Frontier, N.; Nikpaljevic, N.; Vujović, A. Bottlenose dolphins and Striped Dolphins: Species Distribution, Behavioural Patterns, Encounter Rates, Residency Patterns and Hotspots in Montenegro, South Adriatic; Marine Mammals Research Association: Bar, Montenegro, 2017.

13. Reeves, R.R.; Smith, B.D.; Crespo, E.A.; Notarbartolo di Sciara, G. Dolphins, Whales and Porpoises: 2002-2010 Conservation Action Plan for the World's Cetaceans; IUCN: Gland, Switzerland, 2010.

14. Bearzi, G.; Holcer, D.; Notarbartolo Di Sciara, G.N. The role of historical dolphin takes and habitat degradation in shaping the present status of northern Adriatic cetaceans. Aquat. Conserv. Mar. Freshw. Ecosyst. 2004, 14, 363-379, doi:10.1002/aqc.626.

15. Natoli, A.; Birkun, A.; Aguilar, A.; Lopez, A.; Hoelzel, A.R. Habitat structure and the dispersal of male and female bottlenose dolphins (Tursiops truncatus). Proc. R. Soc. B Biol. Sci. 2005, 272, 1217-1226, doi:10.1098/rspb.2005.3076. 
16. Gaspari, S.; Holcer, D.; Mackelworth, P.; Fortuna, C.; Frantzis, A.; Genov, T.; Vighi, M.; Natali, C.; Rako, N.; Banchi, E.; et al. Population genetic structure of common bottlenose dolphins (Tursiops truncatus) in the Adriatic Sea and contiguous regions: Implications for international conservation. Aquat. Conserv. Mar. Freshw. Ecosyst. 2015, 25, 212-222, doi:10.1002/aqc.2415.

17. Genov, T.; Wiemann, A.; Fortuna, C.M. Towards identification of the bottlenose dolphin (Tursiops truncatus) population structure in the north-eastern Adriatic Sea: Preliminary results. Varstvo Narave 2009, 22, 73-80.

18. Franklin, J. Mapping Species Distributions: Spatial Inference and Prediction; Cambridge University Press: Cambridge, UK, 2010.

19. Gómez De Segura, A.; Hammond, P.S.; Raga, J.A. Influence of environmental factors on small cetacean distribution in the Spanish Mediterranean. J. Mar. Biol. Assoc. 2008, 88, 1185-1192, doi:10.1017/S0025315408000386.

20. Azzellino, A.; Airoldi, S.; Lanfredi, C.; Podestà, M.; Zanardelli, M. Deep-Sea Research II Cetacean response to environmental and anthropogenic drivers of change: Results of a 25-year distribution study in the northwestern Mediterranean Sea. Deep. Sea Res. Part II: Top. Stud. Oceanogr. 2017, 146, 104-117, doi:10.1016/j.dsr2.2017.02.004.

21. Vincenzi, S.; Zucchetta, M.; Franzoi, P.; Pellizzato, M.; Pranovi, F.; De Leo, G.A.; Torricelli, P. Application of a Ranom Forest algorithm to predict spatial distribution of the potential yield of Ruditapes philippinarum in the Venice lagoon, Italy. Ecol. Model. 2011, 222, 1471-1478, doi:10.1016/j.ecolmodel.2011.02.007.

22. Balance, L.T. Habitat use patterns and ranges of the bottlenose dolphin in the Gulf of California, Mexico. Mar. Mammal Sci. 1992, 8, 262-274, doi:10.1111/j.1748-7692.1992.tb00408.

23. Fortuna, C.; Holcer, D.; Filidei, E., Jr.; Donovan, G.; Tunesi, L. First Cetacean Survey in the Adriatic Sea: Summer 2010. In Proceedings of the 7th Meeting of the ACCOBAMS Scientific Committee, Pais, Monaco, 21-31 March 2011; p. 16.

24. Canadas, A.; Sagarminaga, R.; Garica-Tiscar, S. Cetacean distribution related with depth and slope in Mediterranean waters off southern Spain. Deep. Sea Res. Part I Oceanogr. Res. Pap. 2002, 49, 2053-2073, doi:10.1016/S0967-0637(02)00123-1.

25. Gannier, A. Summer distribution and relative abundance of delphinids in the Mediterranean Sea. Revu d'Ecologie 2005, 60, 223238.

26. Trincardi, F.; Campiani, E.; Correggiari, A.; Foglini, F.; Maselli, V.; Remia, A. Bathymetry of the Adriatic Sea: The legacy of the last eustatic cycle and the impact of modern sediment dispersal. J. Maps 2013, 10, 151-158, doi:10.1080/17445647.2013.864844.

27. Payton, A.; Mclaiughlin, K. The oceanic phosphorus cycle. Chem. Rev. 2007, 107, 563-576.

28. Pitchford, J.L.; Howard, V.A.; Shelley, J.K.; Serafin, B.J.; Coleman, A.T.; Solangi, M. Predictive spatial modelling of seasonal bottlenose dolphin (Tursiops truncatus) distribution in the Mississippi Sound. Aquat. Conserv. Mar. Freshw. Ecosyst. 2015, 26, 289-306, doi:10.1002/aqc.2547.

29. Hornsby, F.E.; McDonald, T.L.; Balmer, B.C.; Speakman, T.R.; Mullin, K.D.; Rosel, P.E.; Wells, R.S.; Telander, A.C.; Marcy, P.W.; Schwacke, L.H.; et al. Using salinity to identify common bottlenose dolphin habitat in Barataria Bay, Louisiana, USA. Endanger. Species Res. 2016, 33, 181-192, doi:10.3354/esr00807.

30. Holcer, D.; Fortuna, C.M.; Mackelworth, P.C. Important Areas for Conservation of Cetaceans, Sea Turtles and Giant Devil Rays in the Adriatic Sea: Summary of Existing Knowledge; UNEP/MAP-RAC/SPA Internal report. Contract N 08/RAC/SPA_2013 MedOpenSeas; 2014; 67p. 